\title{
Industrial Wastewater Treatment Using Hydrodynamic Cavitation and Heterogeneous Advanced Fenton Processing
}

Anand G. Chakinala ${ }^{1}$, Parag R. Gogate ${ }^{2}$, Arthur E. Burgess ${ }^{1}$, David H. Bremner ${ }^{1 *}$

${ }^{1}$ School of Contemporary Sciences, University of Abertay Dundee, DD1 1HG Dundee, United Kingdom

${ }^{2}$ Chemical Engineering Department, Institute of Chemical Technology, University of Mumbai, Mumbai, 400019 India

* $\quad$ Corresponding author: Tel.: +44 1382 308667; Fax: +44 1382308663

E-mail: d.bremner@abertay.ac.uk (David H. Bremner) 


\begin{abstract}
:
A combination of hydrodynamic cavitation and heterogeneous Advanced Fenton Process (AFP) based on the use of zero valent iron as the pseudo-catalyst has been investigated for the treatment of real industrial wastewater. The effect of various operating parameters such as inlet pressure, temperature, and the presence of copper windings as additional oxidant on the extent of mineralization as measured by total organic carbon (TOC) content have been studied with the aim of maximizing the extent of degradation. It has been observed that elevated pressures, higher operating temperature and the absence of copper windings are more favourable for a rapid TOC mineralization. A new approach of latent remediation has also been investigated where hydrodynamic cavitation is only used as a pretreatment with an aim of reducing the total cost of remediation. It has been observed that this novel approach of latent remediation works very well with about $50 \%$ to $60 \%$ removal of TOC using only an initial 15 min treatment by hydrodynamic cavitation.
\end{abstract}

Key words: Hydrodynamic Cavitation, Advanced Fenton Process, Industrial Wastewater treatment, Iron metal catalyst, Latent Remediation 


\section{Introduction}

Due to an increasing awareness about the environment and more stringent environmental regulations, treatment of industrial wastewater is a key aspect of current research. Much work has been done in developing and testing newer techniques and their combinations for wastewater treatment either individually or as a supplementary role to conventional biological and chemical methods [1-2]. Cavitation is one such recent technique which has been found to be highly beneficial in wastewater treatment and has attracted considerable research interest [3]. Cavitation can be described as the formation, growth and subsequent collapse of cavities releasing large amounts of energy, locally creating conditions similar to hot spots and also generating strong oxidizing conditions by way of production of hydroxyl radicals and also hydrogen peroxide. Cavitation generated using ultrasound irradiation has been categorized as acoustic cavitation whereas when generated using hydrodynamic means (interchange of flow energy and pressure energy), it is described as hydrodynamic cavitation. A great deal of research has indeed focussed on the application of acoustic cavitation for wastewater treatment [3-10] for a variety of pollutants but only a few studies have reported the use of hydrodynamic cavitation for wastewater treatment [11-12] with much better energy efficacy compared to the acoustic cavitation reactors. It should also be noted here that though cavitational reactors have been reported to be highly successful in the laboratory these still have not foun applications on an industrial scale mostly due to comparatively high costs and problems associated with efficient operation at levels of power dissipation required for treatment [13]. The efficacy of cavitational reactors can be significantly enhanced by combining cavitation with other oxidation processes or by using catalysts and/or additives. With this intensification, cavitation can be a suitable technology for degradation of wastewater streams or, at the minimum, it can be used for lowering the toxicity levels of the effluent stream so that conventional biological oxidation can be readily 
applicable [14]. In our earlier recent work, a novel combination of hydrodynamic cavitation reactors and the advanced Fenton process was applied, at an operating capacity of $4 \mathrm{~L}$, to the destruction of real industrial wastewater procured from a commercial organization in the UK [15]. Hydrodynamic cavitation was generated using a liquid whistle reactor whereas the Advanced Fenton process (AFP) utilized zero valent iron metal in the form of scrap iron pieces as the heterogeneous catalyst [16-18] with an aim of reduction in the overall cost of the treatment. It has been observed that hydrodynamic cavitation was found to play a supplementary role in enhancing the efficacy of the AFP and the combination of the two resulted in higher overall extents of degradation. The current research is a continuation of the earlier work and utilizes an inbuilt unit for generation of hydrodynamic cavitation (Hydrocavitator) with a maximum operating capacity of $25 \mathrm{~L}$. As cavitational reactors have been found to be cost intensive [13], an novel approach of latent remediation has been investigated wherein the treatment time with hydrodynamic cavitation reactors has been kept at a minimum with an aim of achieving overall lower costs of treatment.

\section{Materials and Methods}

\subsection{Experimental Setup}

Hydrodynamic cavitation was generated using an in-house constructed unit termed the Hydrocavitator which has a feed vessel tank with maximum capacity of $25 \mathrm{~L}$ and operates in a re-circulation mode. Effluent from the feed tank is pumped using a triplex plunger pump (SPECK NP25) with a maximum discharge pressure of 4,500 psi and passes through an orifice unit (orifice area about $7.0 \times 10^{-2} \mathrm{~m}^{2}$ ) followed by a catalyst bed and finally back to the feed tank. An external heat exchanger unit is also provided to control the temperature in the feed vessel tank, which is necessary as cavitation results in the production of heat thereby 
increasing the temperature of the effluent stream. A schematic representation of the reactor assembly is shown in Figure 1.

\subsection{Characteristics of Industrial wastewater:}

The experimental studies were performed to evaluate the efficacy of the process for degradation of industrial wastewater effluent obtained from a local site (details not given due to confidentiality issues). The current investigation is very important in the context of application to wastewater treatment as the majority of the reported literature deals with simulated effluents and the results may or may not be reproduced for real industrial applications due to the presence of trace components such as radical scavengers.

The effluent stream used in the present work consisted of a complex mixture containing substituted phenolic compounds with a $\mathrm{pH}$ of 1.7 , an initial COD of $42,000 \mathrm{mg} / \mathrm{L}$ and TOC of 14,000 mg/L. COD indicates the concentration of all organic compounds which can be fully oxidized using strong oxidizing agents whereas TOC usually indicates the amount of all the organics present in the system.

\subsection{Experimental Methodology}

All experiments (except for latent remediation studies; see below) were carried out with $8 \mathrm{~L}$ of wastewater (diluted accordingly with fresh water), for a period 3-5 h reaction time with zero valent iron pieces $(150 \mathrm{~g} ; 100$ pieces of $1 \mathrm{~cm} \times 2 \mathrm{~cm}, \mathrm{~L}-$ shaped having thickness of $0.10 \mathrm{~cm}$ ) and $\mathrm{H}_{2} \mathrm{O}_{2}$ (usually $1900 \mathrm{mg} / \mathrm{L}$ unless specified otherwise). The concentration of $\mathrm{H}_{2} \mathrm{O}_{2}$ was found to be optimum in our earlier investigations on a smaller scale [15]. Dilute solutions of sulphuric acid (2M) and sodium hydroxide (2M) were used for the adjustment of $\mathrm{pH}$. The temperature was maintained constant using an external cooling ice bath. At defined time intervals, samples were taken and analysed for TOC content present in the solution, as 
complete mineralization of the effluent stream was the main objective of the investigation. The extent of mineralization was determined by direct injection of the filtered samples into the heated persulphate-type $\left(100{ }^{\circ} \mathrm{C}\right)$ TOC analyser (Model 700 , OI Analytical).

\section{Results and Discussion}

The experimental results obtained using varying operating parameters viz. inlet pressure into the system, operating temperature of the reactor and the role of added copper windings as an additional oxidant for AFP as well as the new process termed "latent remediation" are discussed below.

\subsection{Effect of initial pressure:}

The effect of different initial Hydrocavitator pressures in conjunction with the AFP was investigated over the range of $500-1500$ psi and the obtained results are depicted in Figure 2. It is clear from the figure that higher inlet pressures are effective in the rapid mineralization of the wastewater. Maximum TOC removal ratio was obtained at $1500 \mathrm{psi}$ (about $60 \%$ removal) whereas the extent of TOC removal is $52 \%$ and $50 \%$ at 1000 psi and 500 psi respectively under otherwise similar experimental conditions. The trends in the variation of extent of TOC removal with inlet pressures are in close agreement with those reported in the literature. Senthilkumar and Pandit [19] as well as Vichare et al. [20], investigated the decomposition of aqueous potassium iodide solution, and reported an increase in the extent of iodine liberation with higher inlet pressure when using a multiple orifice plate hydrodynamic cavitation reactor. Jyoti and Pandit [21] also reported superior disinfection efficacy by a hydrodynamic cavitation reactor with higher inlet pressures. The increase in the extent of degradation can be attributed to the enhanced cavitational activity at higher pressures. Bubble dynamics studies [22] have indicated that the cavitational intensity 
generated on the collapse of the cavity increases as a result of raised inlet pressure in the system. Due to an increase in the cavitational collapse intensity, higher temperatures and pressure pulses are generated resulting in enhanced dissociation of the water molecules trapped in the cavity thereby leading to a higher concentration of hydroxyl radicals existing in the reactor. Also higher cavitational activity is expected to have better activation effects on the advanced Fenton process in terms of higher particle size reduction leading to enhanced surface area for Fenton chemistry.

\subsection{Effect of Operating Temperature:}

Operating temperature is another key parameter which affects the intensity of hydrodynamic cavitation as well as efficacy of Fenton chemistry. The effect of operating temperature was investigated at two different temperatures: $20{ }^{\circ} \mathrm{C}$ and $30{ }^{\circ} \mathrm{C}$. It is observed that the extent of mineralization increased with a change in the operating temperature from 20 ${ }^{\circ} \mathrm{C}$ to $30{ }^{\circ} \mathrm{C}$ and the results (not shown) are similar to those given for mineralization with time of treatment (figure 2). The extent of mineralization at the end of $150 \mathrm{~min}$ was about $50 \%$ higher at $30{ }^{\circ} \mathrm{C}$ as compared to an operating temperature of $20^{\circ} \mathrm{C}$. The enhanced efficacy of the advanced Fenton process combined with hydrodynamic cavitation at higher operating temperatures can be attributed to controlling contributions from the advanced Fenton process as compared to hydrodynamic cavitation. It is expected that the cavitational intensity decreases with an increase in the temperature due to formation of vaporous cavities which collapse less violently [23-25]. However, the efficacy of the Fenton process in terms of generation of hydroxyl radicals is significantly enhanced at higher operating temperatures [26-28]. Sun et al. [26] have reported that the rate constant for degradation of p-nitroaniline increased by almost $100 \%$ with an increase in the temperature from $20{ }^{\circ} \mathrm{C}$ to $30{ }^{\circ} \mathrm{C}$. The current study about the effect of operating temperature has enabled us to establish the 
controlling contribution from the advanced Fenton process for overall extent of mineralization, amongst the two counteracting effects of temperature on cavitation and the Fenton process. Sun et al. [29] have also reported similar behaviour for the combined process of ultrasound assisted Fenton oxidation of acid black 1. The decolouration efficiency was shown to increase marginally from $92.39 \%$ to $99.14 \%$ as a consequence of increasing the temperature from $20{ }^{\circ} \mathrm{C}$ to $40{ }^{\circ} \mathrm{C}$.

\subsection{Effect of presence of copper windings as additional oxidant:}

As the advanced Fenton process was the controlling process, it was thought desirable to investigate the effect of the presence of additional pseudo-catalyst in the form of copper under otherwise optimised advanced Fenton process parameters such as iron and hydrogen peroxide loadings [15]. It has also been reported recently that use of copper in the presence of hydrogen peroxide results in generation of hydroxyl radicals [30] via a similar mechanism of oxidation.

Figure 3 shows the extent of mineralization in the presence and absence of copper windings on the iron pieces by the combination of the advanced Fenton process and hydrodynamic cavitation. It is observed that the combination of copper and iron pieces in the modified advanced Fenton process has a negative impact on the mineralization of organic pollutants present in wastewater. From the figure, it can be seen that about $60 \%$ of TOC was removed in the presence of iron pieces alone and the decrease in TOC was only $40 \%$ with copper windings on the iron pieces in 150 min of treatment. The obtained results can be explained on the basis of relative rates of hydroxyl radical generation due to the presence of iron and copper. It is well accepted fact that the rate of hydroxyl radical generation and hence the extent of TOC mineralization is much higher in the presence of iron as compared to copper metal. Dai et al. [31] have reported that degradation of pentachlorophenol was much 
faster in the presence of elemental iron as compared to copper metal. Guo et al. [32] have also confirmed the beneficial effects of iron based Fenton chemistry for 2,4-dinitrophenol removal. In the current scenario, the presence of copper windings on the iron pieces (with an aim of increasing the overall loading of the catalyst) blocks some surface of iron catalyst being exposed to hydrogen peroxide. Since the formation of hydroxyl radicals in the advanced Fenton process is a surface phenomenon [16-18], the blockage of iron surface by copper results in lowering of the extent of release of the free radicals over the considered treatment time, thereby lowering the overall extent of mineralization.

\subsection{Latent Remediation studies:}

Cavitation, though very effective in wastewater treatment, is often a cost intensive operation. To minimize the overall costs of treatment in the present combined hydrodynamic cavitation and advanced Fenton process (HCAFP), a new approach of Latent Remediation was tested where the treatment time of hydrodynamic cavitation was kept at a minimum. The effect of different treatment times (continuous treatment and 15 min of treatment time) on the extent of mineralization is depicted in Figure 4. It is evident from the figure that about $70 \%$ of the initial TOC was removed by the continuous treatment of the wastewater for a treatment time of $150 \mathrm{~min}$. However, when the wastewater was treated only for 15 min using the Hydrocavitator and AFP under similar experimental conditions and treatment with hydrocavitator/AFP i.e. re-circulation through the orifice chamber and bed of iron catalyst, was stopped after $15 \mathrm{~min}$, subsequent analysis of the samples indicated that TOC mineralization did not cease. It can be seen from the figure that the initial TOC content was reduced to $53 \%$ after a further 135 min of only storage i.e. without any treatment. During the first 15 min of treatment, the extent of TOC diminution was $30 \%$ while the remainder occurred in storage - a process which can be described as latent remediation. The process of 
latent remediation can be explained on the basis of the contributing actions of hydrodynamic cavitation and iron particles in the presence of hydrogen peroxide. During first 15 minutes of treatment time, iron metal is corroded in the presence of dilute acid and hydrogen peroxide and forms ferrous ions in solution (Eqn 1) which then generate hydroxyl radicals and other oxidising species in the system via classical Fenton chemistry (Eqn 2). Ferric ions produced in Eqn 2 are then converted back to ferrous ions by interaction with zero valent iron (Eqn 3) [15]. These oxidizing species present in the effluent mixture along with the dissolved iron and remaining hydrogen peroxide initiates a series of radical reactions which ensures presence of oxidizing species to continue TOC mineralization. It should be also noted here that out of the initially added hydrogen peroxide in the system, some hydrogen peroxide will be utilized by Fenton chemistry and some due to thermal dissociation in the presence of cavitating conditions. The remaining hydrogen peroxide along with some hydrogen peroxide generated due to hydrodynamic cavitation (the amount is expected to be substantially lower) contributes to the continuous formation of the oxidizing species according to the reaction scheme illustrated below. This hypothesis is supported by the results obtained with variation of the treatment time with the combined advanced Fenton process and hydrodynamic cavitation. When the treatment time is increased to $30 \mathrm{~min}$ instead of $15 \mathrm{~min}$, the efficacy of latent remediation decreased possibly due to greater decomposition of hydrogen peroxide. The extent of TOC mineralization using the latent remediation approach was only $30 \%$ when 30 min treatment was used as against $47 \%$ when 15 min treatment was used. 


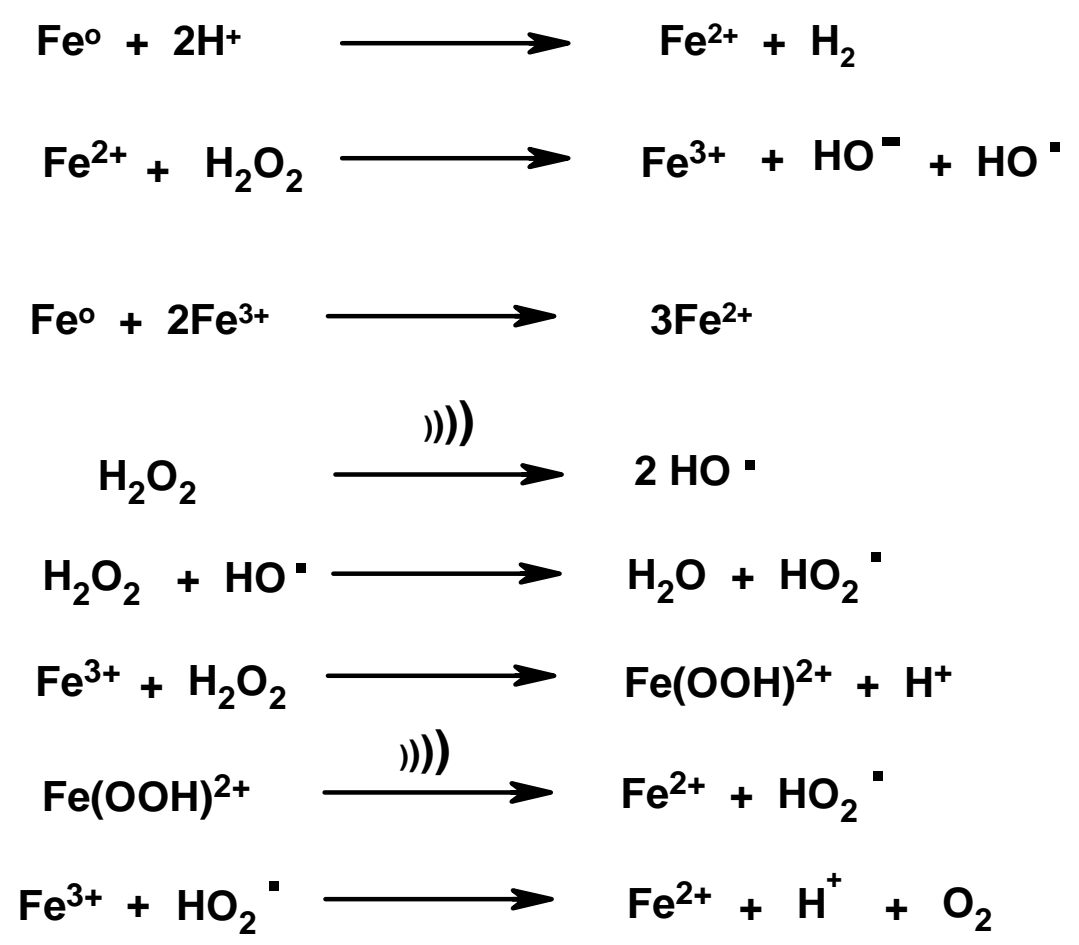

\section{Conclusions:}

The combination of hydrodynamic cavitation generated by an in-house built Hydrocavitator and advanced Fenton oxidation can be effectively used for treatment of real industrial wastewater samples. Studies of the effects of different operating parameters and treatment approaches have enabled us to draw following important conclusions:

- Higher inlet pressures result in greater cavitational activity contributing to enhanced hydroxyl radical generation and hence increased TOC mineralization of the effluent.

- Higher operating temperatures are preferred indicating that the controlling contribution between the two oxidizing mechanisms is due to the advanced Fenton process

- The presence of copper windings on iron pieces as an alternative catalyst did not result in beneficial effects possibly attributed to the blockage of the iron surface for generation of hydroxyl radicals. 
- A novel approach of latent remediation is highly effective in overall mineralization. Short treatment times of $15 \mathrm{~min}$ are more beneficial than the 30 min treatment time thereby minimising the energy costs.

The results achieved using the hydrocavitator and the advanced Fenton process are particularly beneficial and path breaking due to the fact that the overall unit operates in a continuous mode and hence large volumes of contaminated water can be treated in a cost effective manner using the approach of Latent Remediation.

\section{Acknowledgements}

AGC and DHB wish to acknowledge the funding of Scottish Enterprise under the Proof of Concept extension (POC+) award and PRG wishes to acknowledge the support of the Department of Science \& Technology, India and The Royal Society, UK for sponsoring the visit to the University of Abertay Dundee under the India UK Science Networks Scheme (Part II).

\section{References:}

(1) P.R. Gogate, A.B. Pandit, Adv. Env. Res. 8 (2004) 501.

(2) P.R. Gogate, A.B. Pandit, Adv. Env. Res. 8 (2004) 553.

(3) Y.G. Adewuyi, Ind. Eng. Chem. Res. 40 (2001) 4681.

(4) C. Petrier, Y. Jiang, M-F. Lamy, Env. Sci. Technol. 32 (1998) 1216.

(5) M. Sivakumar, A.B. Pandit, Ultrason. Sonochem. 8 (2001) 233.

(6) N.N. Mahamuni, A.B. Pandit, Ultrason. Sonochem. 13 (2006) 165.

(7) P. R. Gogate, S. Mujumdar, J. Thampi, A. M. Wilhelm, A. B. Pandit, Sep. Pur. Tech., 34 (2004) 25

(8) R. Kidak, N.H. Ince, Ultrason. Sonochem. 13 (2006) 195 
(9) C. Petrier, A. Francony, Wat. Sci. Tech., 35 (1997) 175.

(10) M. H. Entezari, C. Pétrier, Ultrason. Sonochem., 10 (2003) 241.

(11) M. Sivakumar, A.B. Pandit, Ultrason. Sonochem. 9 (2002) 123.

(12) K.M. Kalumuck, G.L. Chahine, J. Fluids Eng. 122 (2000) 465.

(13) T.J. Mason, Ultrason. Sonochem. 7 (2000) 145

(14) P.R. Gogate, Ultrason. Sonochem. 15 (2008) 1

(15) A.G. Chakinala, P.R. Gogate, D.H. Bremner, A.E. Burgess, Ultrason. Sonochem. 15 (2008) 49

(16) D.H Bremner, A.E. Burgess, D. Houllemare, K.C. Namkung, App. Catal. B: Env., 63 (2006) 15.

(17) K.C. Namkung, A.E. Burgess, D.H Bremner, Environ. Tech., 26 (2005) 341.

(18) K.C. Namkung, A.E. Burgess, D.H. Bremner, H. Staines, Ultrason. Sonochem. 15 (2008) 171

(19) P. Senthilkumar, M. Sivakumar, A.B. Pandit, Chem. Eng. Sci. 55 (2000) 1633

(20) N.P. Vichare, P.R. Gogate, A.B. Pandit, Chem. Eng. Tech. 23 (2000) 683.

(21) K.K. Jyoti, A.B. Pandit, Biochem. Eng. J. 7 (2001) 201

(22) P.R. Gogate, A.B. Pandit, AIChE J. 46 (2000) 1681.

(23) K. S. Suslick, M. M. Mdleleni, J. T. Ries, J. Am. Chem. Soc., 119 (1997), 9303.

(24) M. H. Entezari, P. Kruus, Ultrason. Sonochem., 3 (1996), 19.

(25) N. P. Vichare, P. Senthilkumar, V.S. Moholkar, P. R. Gogate, A. B. Pandit, Ind. Eng. Chem. Res., 39 (2000), 1480

(26) J-H. Sun, S-P. Sun, M-H. Fan, H-Q. Guo, L-P. Qiao, R-X. Sun, J. Haz. Mat., 148 (2007), 172

(27) H. Zhang, H.J. Choi, C.P. Huang, J. Hazardous Materials, 125 (2005), 166 
(28) F.J. Rivas, F. Beltran, O. Gimeno, F. Carvalho, J. Environ. Sci. Health, Part A:

Environ. Sci. Eng., 38 (2003), 371

(29) J-H. Sun, S-P. Sun, J-Y. Sun, R-X. Sun, L-P. Qiao, H-Q. Guo, M-H. Fan, Ultrason. Sonochem., 14 (2007), 761

(30) J.K. Kim, I.S. Metcalfe, Chemosphere, 69 (2007) 689-96

(31) Y. Dai, F. Li, F. Ge, F. Zhu, L. Wu, X. Yang, J. Hazardous Mat. B137 (2006) 14241429

(32) Z. Guo, Z. Zheng, S. Zheng, W. Hu, R, Feng, Ultrason. Sonochem. 12 (2005) 461465 


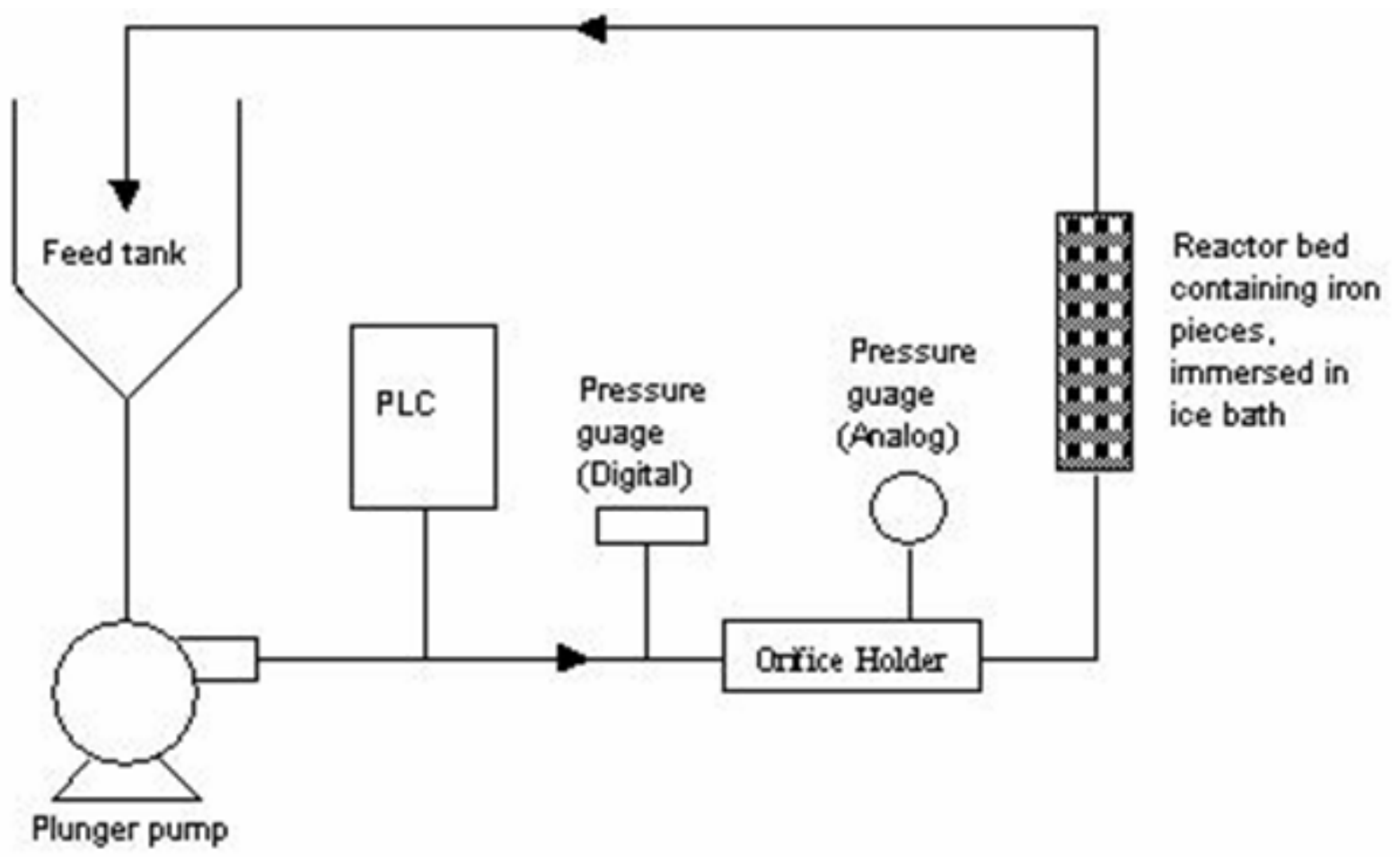

Figure 1: Schematic representation of the Experimental Setup 


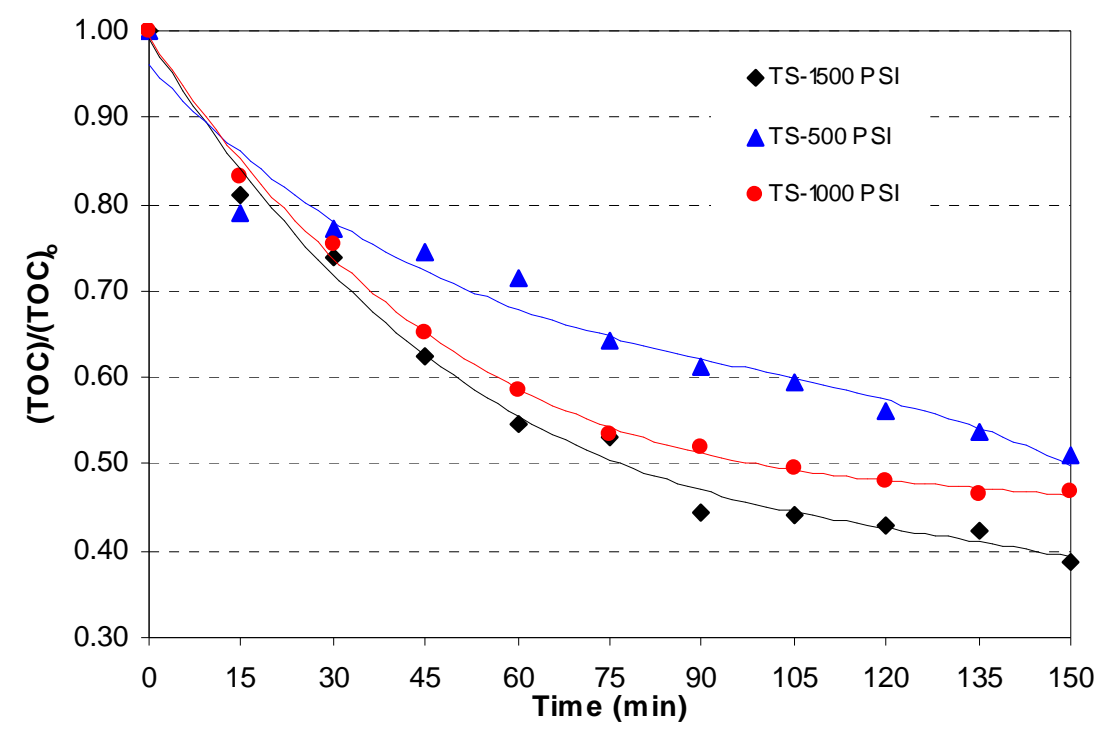

Figure 2: Effect of different Hydrocavitator pressures on the extent of mineralization.

(Experimental conditions: initial $\mathrm{pH}-2.5$, sample volume $-8 \mathrm{~L}$, iron pieces -100 (150 g), dilution factor -25 times, $\mathrm{H}_{2} \mathrm{O}_{2}-1900 \mathrm{mg} / \mathrm{L}$, temperature $-30 \pm 5^{\circ} \mathrm{C}$ ) 


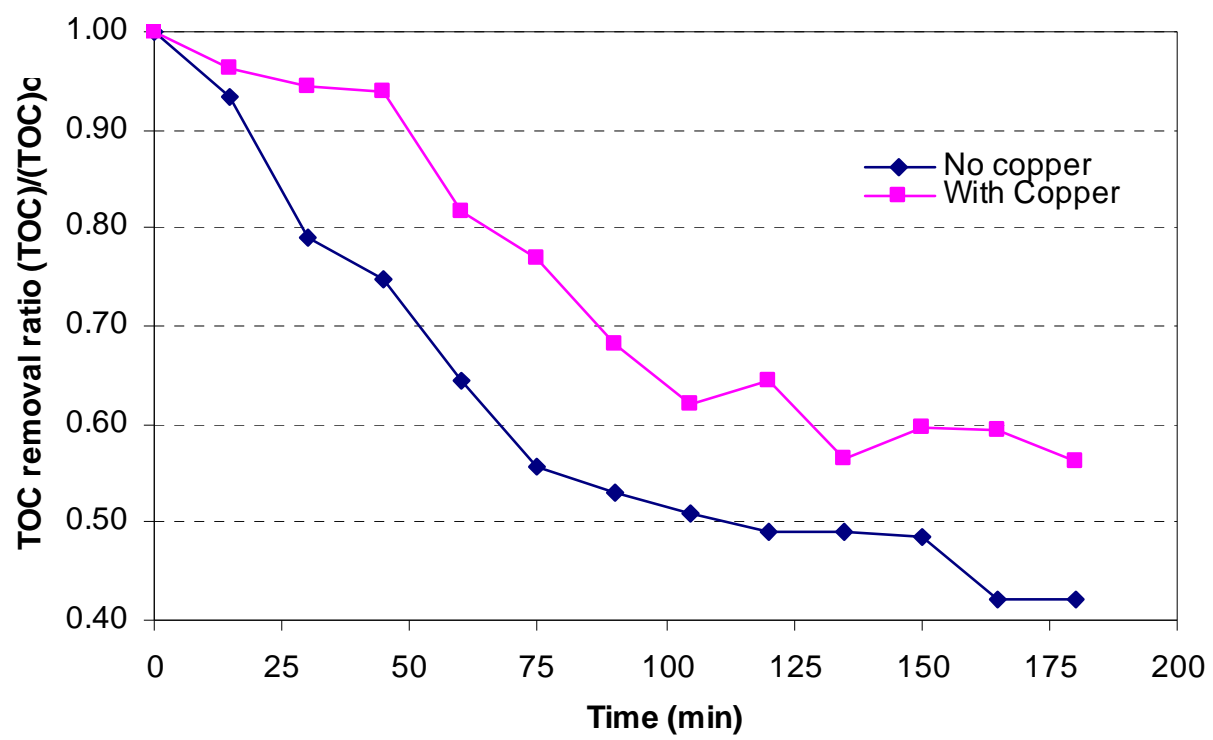

Figure 3: Effect on the extent of mineralization of copper windings on the iron.

(Experimental conditions: initial $\mathrm{pH}-2.5$, , sample volume $-4 \mathrm{~L}$, iron pieces -50 (75 g), copper wire $-5.5 \mathrm{~g}$, pressure - $1500 \mathrm{psi}$, dilution factor - 25 times, $\mathrm{H}_{2} \mathrm{O}_{2}-1900 \mathrm{mg} / \mathrm{L}$, temperature $-30 \pm 5^{\circ} \mathrm{C}$ ) 


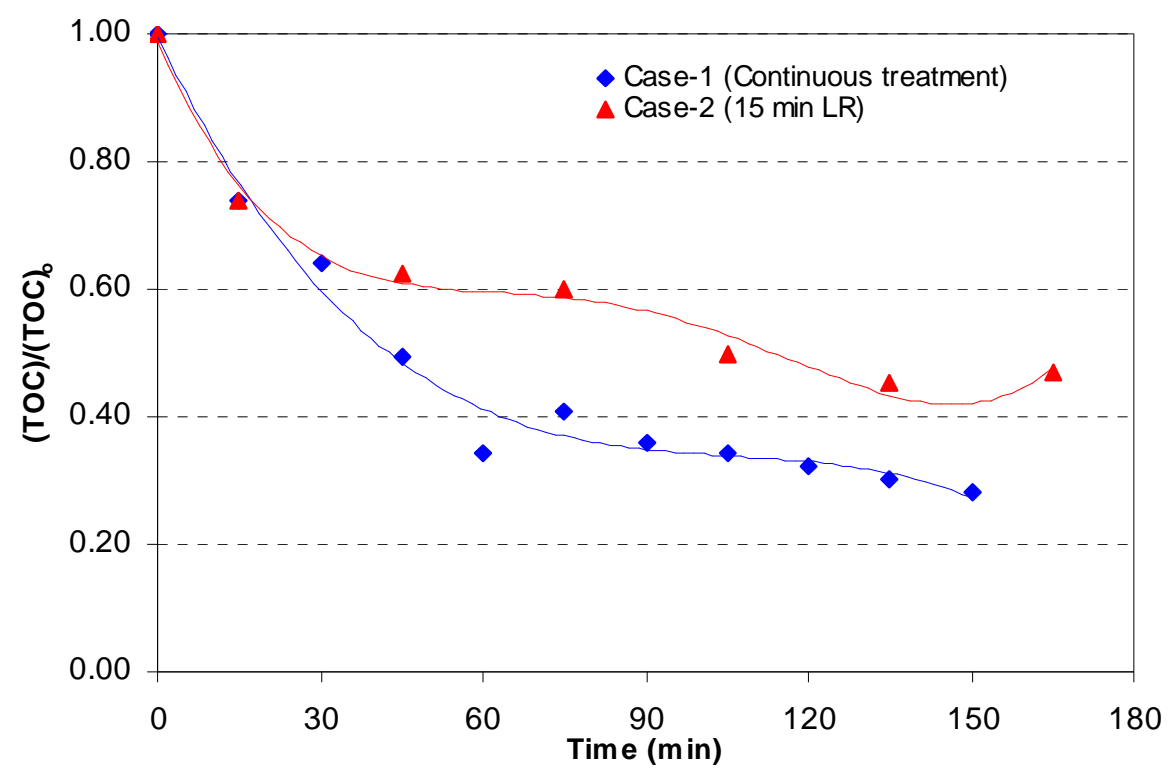

Figure 4: Effect of different treatment times on the extent of mineralization.

(Experimental conditions: initial $\mathrm{pH}-2.5$, sample volume $-8 \mathrm{~L}$, iron pieces -100 (150 g), dilution factor -25 times, $\mathrm{H}_{2} \mathrm{O}_{2}-1900 \mathrm{mg} / \mathrm{L}$, temperature $-30 \pm 5^{\circ} \mathrm{C}$ ) 